\title{
InSTANTÂNEOS DE CERTA COPACABANA ${ }^{\star}$
}

\author{
Danichi Hausen Mizoguchi ${ }^{\star \star}$
}

\begin{abstract}
Resumo
O artigo propõe que, a partir de um passeio pelo bairro de Copacabana, problematizações referentes à experiência urbana contemporânea sejam explicitadas. Tomam-se os dispositivos dos muros e grades que a cada dia mais se espalham pelas cidades a fim de que, na especificidade de determinado território, os embates entre as segmentações e as resistências possam ser tensionados, apresentados e narrados como importantes peças no maquinário subjetivo dos tempos e espaços a que chamamos nossos. Tais narrativas dão-se a partir de uma metodologia de pesquisa a qual dispara da experiência de errância no cotidiano urbano, buscando imagens de uma delicada empiria.
\end{abstract}

Palavras-chave: Copacabana; muros e grades; cidade; contemporâneo; narrativa.

\section{Flashes of Certain Copacabana}

\begin{abstract}
The article proposes that, based on a walk around the Copacabana area, issues related to the contemporary urban experience become explicit. Walls and bars mechanisms, which are spread throughout cities everyday, are taken in order to - in the specificities of a certain territory - push, present and narrate conflicts between resistances and segmentations as important parts of the subjective machinery of spaces and times we call ours. Those narratives are performed based on a research methodology that begins at the errancy on urban daily life, searching images of a delicate empiry.
\end{abstract}

Keywords: Copacabana; walls and bars; city; contemporary; narrative.

\footnotetext{
* O presente artigo é conseqüência da reelaboração de um capítulo da dissertação de mestrado intitulada Segmentaricidades: passagens do Leme ao Pontal, produzida sob a orientação do professor Luis Antonio Baptista junto ao Programa de Pós-Graduação em Psicologia da Universidade Federal Fluminense. Disponível em http://www.slab.uff.br/dissertacoes/2007/ Danichi.pdf . Trabalho realizado com apoio financeiro da CAPES.

$\star \star$ Psicólogo. Doutorando no programa de Estudos da Subjetividade do Departamente de Psicologia da Universidade Federal Fluminense. Leciona no curso de Psicologia das Faculdades Integradas Maria Thereza. Endereço: Rua Visconde do Rio Branco 869 - São Domingos - Niterói, RJ - Brasil.

E-mail: danichihm@hotmail.com
} 


\begin{abstract}
Copacabana e Centro, os dois lugares mais democráticos do Rio onde a beleza do caos humano se mostra organizada na deliciosa convivência de todas as presenças. O Centro durante o dia e Copacabana vinte e quatro horas. Copacabana por isso é a capital da cidade do Rio de Janeiro, exemplo de todas as tradições e circunstâncias que caracterizam a beleza como quesito cabeça-de-chave no pensamento-sentimento da cidade. E também exemplo de todas as tradições e circunstâncias que caracterizam o caos como o outro quesito para se pensar e sentir esse Rio de Janeiro (FAWCETT, 2002, p. 36).
\end{abstract}

O passeio como acto, como política, como experimentação, como vida (DELEUZE; PARNET, 2004, p 43).

Tome-se o trecho de terra localizado entre o Oceano Atlântico e os morros de São João, da Saudade, dos Cabritos, do Cantagalo e do Pavão. Ali, centenas de milhares de pessoas vivem e circulam. Um sem número de prédios residenciais e comerciais arranha o céu. O negrume da fumaça e renitentes resquícios de maresia batalham no ar. Nas ruas, a mistura das gentes e dos automóveis compõe um fluido que quase faz crer na existência do moto-contínuo.

Certa feita a inóspita praia de Sacopenapan, ora uma das regiões mais agitadas da cidade de São Sebastião do Rio de Janeiro: vêem-se ainda os morros e se vê ainda o mar, mas onde o matagal acostumara-se a dar à luz o verde, vêem-se predominantes os tons escuros acinzentados do asfalto e das armações de concreto e a estética da ginga de duas ou três favelas. Muita gente é o que se vê no bairro quase que a qualquer hora do dia: turistas brasileiros e estrangeiros, pedintes sem-teto, maltrapilhos de toda ordem, anônimos cidadãos de classe média das mais diversas faixas etárias, velhos pescadores saudosos da Princesinha do Mar. Copacabana é uma miríade de existências.

Interessante, nesse sentido, atentar para os modos como o bairro - já antigo, inserido em um projeto de modernidade para o Rio de Janeiro - responde às problematizações e imperativos urbanos contemporâneos. Tarefa importante: como afirma Luis Antonio Baptista (1999, p. 123):

[...] as cidades dos nossos dias, como as do passado, são territórios de fecundos conflitos, experimentações, lugar onde se produz a face do diverso, do estranho, do familiar, do estrangeiro. Local ao mesmo tempo de fabricação de práticas para acolhê-los, dar corpo às suas faces ou dissipá-los.

Se assim é, o que poderia ensinar o tradicional bairro da zona sul carioca acerca dos modos de existência atuais? Como e com que intensidade nele estão modulados os muros e grades que tanto e cada vez mais territorializam os espaços citadinos e dissipam as faces do diverso? Será que ali se poderiam avistar rumores de resistência aos ditames ordenativos que impingem pequenas e violentas segregações cotidianas? Será que ali - vazando por entre os vãos desses muros e grades há algo que se dá a acolher e dar corpo aos fecundos conflitos e experimentações? 
De saída, faz-se necessário dizer que Copacabana surge como consequência da direção imposta à cidade pela reforma urbana promovida pelo prefeito Pereira Passos, fazendo-a correr pelas bordas da Baía de Guanabara e tendo como meta o terreno costeiro ao mar aberto. Nessa época, o fluxo populacional em direção ao bairro, fruto da reforma que pretendia criar um sítio distanciado dos perigos da pobreza que ocupava a área central da cidade, aumentava rapidamente: Copacabana representava o glamour que afirmava o prestígio moderno do Rio de Janeiro e do Brasil. O otimismo consagrava uma cidade aberta: eram tempos nos quais "sentir-se carioca seria sentir-se proprietário dos espaços da cidade" (LESSA, 2000, p. 266). A especulação imobiliária fartava-se: abriam-se ruas, empilhavam-se conjugados, colavam-se prédios uns nos outros. Já no começo da década de 1930, Copacabana era um bairro consolidado, com a quase totalidade dos lotes ocupados. Em relação diretamente proporcional ao aumento da densidade populacional, desapareciam os espaços livres. Já no ano de 1935, reagindo a tal organização espacial, uma comissão de moradores solicitou ao então prefeito Pedro Ernesto a criação de uma praça na avenida Atlântica, entre as ruas Bolívar e Barão de Ipanema. A reivindicação não só não foi atendida como, ao contrário, a área de uma das antigas praças, a Barão de Santa Leocádia, foi ocupada por prédios, na região em que hoje se encontra o cinema Roxy (CARDOSO et al., 1986) - aliás, o único em funcionamento no bairro atualmente. Copacabana e seu crescimento desmesurado não permitiam espaços livres.

Crescendo sem parar no decorrer dos anos 40, 50 e 60, Copacabana significou uma verdadeira revolução urbanística, não porque propusesse um novo modelo de bairro, mas porque sintetizava, em seu espaço, toda a problemática da expansão urbana de uma cidade capitalista subdesenvolvida: crescimento desordenado, alta densidade demográfica, código de obras deficiente e superado, falta de regulamentação, companhias-fantasmas, aventureirismo, crescimento predatório, despreocupação quanto às formas arquitetônicas e à organização do espaço interno etc. [...] Vista durante muito tempo como uma excepcionalidade e como uma disfunção do sistema, Copacabana nada mais era do que a expressão de forças econômicas, sociais e culturais de sua época que irromperam, uma vez liberadas, no cenário urbano (CARDOSO et al., 1986, p. 131).

Não é de hoje, logo, que em Copacabana não há espaço para novos empreendimentos imobiliários. Não causa espanto, por exemplo, que o bairro não sedie nenhum shopping center: quando, em meados da década de 1980, o Rio de Janeiro e o Brasil ingressaram na era dos modernos centros comerciais, em Copacabana já não havia mais lugar para construções que exigissem terrenos extensos. E, pelo mesmo motivo, em Copacabana não se vê outra das mais fortes tendências urbanas atuais: os condomínios horizontais quase auto-sustentáveis - com praças, escolas e quadras esportivas em seu interior, que fazem da vida dentro de grades 
uma realidade - típicos da especulação imobiliária que se efetuou notadamente na Barra da Tijuca nos idos da década de 1990. É de outro modo que o bairro responde - cede e resiste - aos imperativos de segmentação urbana atuais.

A segregação espacial que se operou há quase um século com a criação de Copacabana metamorfoseou-se em metrópole cosmopolita (LAVINAS; RIBEIRO, 1997). O mito paradisíaco que afirmava o bairro representante de uma cidade cantada em prosa e verso como maravilhosa - "nenhuma tem o encanto que tu possuis", compôs Braguinha (1946) na segunda metade da década de 1940 - transformou-se no que o cronista João Antonio, em 1978, com certo mau humor e desgosto, chama de "classe média decadente metida a besta, vale tudo, bairro independente, hong-kong, cabocla, selva" (ANTONIO, 2001, p. 80). De fato, Gilberto Velho (1989, p. 3) parece ter razão quando escreve: "Rejeitada por muitos, extremamente valorizada por outros, Copacabana expressa, dramaticamente, problemas de interação, convívio e tensão social".

Mas, afinal, como está composta em Copacabana essa polifonia que tanto tem a dizer sobre as subjetividades que lá são produzidas? Teriam os tijolos dos muros e os ferros das grades força suficiente para delimitar quem é quem na multidão? Para além de sonhos dourados e ressentimentos de falidas utopias, um passeio errante pelo bairro talvez faça ver os jogos - sujeitos, armas, identidades, virtualidades - que ali se atualizam.

A impressão inicial de ingenuidade na proposta de tal passeio errante não se confirma. Há nela toda uma conceituação profícua a embasar uma direção ética, estética e política de produção de conhecimento, ${ }^{1}$ à qual almeja dar-se numa zona de dupla captura entre singularidades: um corpo curioso e um mundo que o atiça. Sendo fabricada em tal zona, quer prestar-se a escapar da modorra dos grudentos decalques pré-fabricados sempre prontos a serem aderidos a toda e qualquer superfície, diminuindo a miríade possível dos registros a um punhado de expressões prêt-à-porter. Procedimento de pesquisa e tessitura de conhecimentos que - além e aquém da sacralização da verdade - autoriza que a polifonia seja posta à baila no plano dos saberes. Em outras palavras, produção e afirmação de imagens de pensamento (BENJAMIN, 1987) sempre e inevitavelmente inéditas. Para que tal direção ética, estética e política de produção de conhecimento possa se efetivar em estudos sobre a urbanidade, a primeira das apostas aqui feitas é ter os olhos curiosos e atentos ao cotidiano. Claro, já que talvez Marcelo Santana Ferreira (2006, p. 44).esteja certo ao afirmar que "estudar uma época é referir-se aos materiais cotidianos da existência coletiva humana". Mas como habitar e perscrutar o dia-a-dia? Eis a segunda aposta: a errância. Deixar-se ir pela cidade sem buscar o caminho correto que leve à certificação de verdades quaisquer. Jean-Marie Gagnebin (1996, p. 245) destaca tal função definindo que:

[...] somente a experiência do errar, em todos os seus sentidos, nos faz apalpar, como que pelo avesso, a experiência de uma verdade que não seria, primeiramente, a coerência de nosso pensamento, mas sim o movimento mesmo de sua produção. 
Fazendo uso da proposta que Walter Benjamin (1989) aprende com o poeta Charles Baudelaire, trata-se de, a partir da errância e da atenção ao cotidiano, transmutar-se em um pesquisador trapeiro, detendo-se a todo instante no caminho para que se possa recolher o lixo no qual se tropeça e, a partir de tais encontros, ousar narrar: esculpir relatos os quais, como bem explica Ana Cabral (2006, p. 51), podem ser entendidos:

[...] como uma forma artesanal de comunicação, na qual os gestos, as mãos, intervêm ativamente no fluxo do que é dito e plasmam a narrativa em sua condição sui generis, na integralidade de contar a vida, que não é uma, mas composta do movimento de tantas outras em uma singularidade que é o narrador.

Vejamos.

Já é madrugada. Há exus soltos nas quebradas. Dormitando, porteiros guardam prédios. Relaxam, já que, em sua grande maioria, os prédios têm a segurança almejada por seus moradores garantida pelas cercas que os envolvem e os tornam supostamente herméticos. Marcas de dois tempos: construções art déco protegidas por grades sem ferrugem. Pestanejando, os funcionários abrem o portão para os condôminos boêmios que tocam a campainha e pedem autorização para entrar no espaço privado e voltar ao lar. Meio do turno, o funcionário deixa a sentinela: fuma um cigarro e conversa com o vizinho de trabalho. Tomam a calçada como sala de estar. Na lentidão madrugadeira o papo escorre preguiçoso. Daqui a algumas horas o fuzuê acalorado fará tudo - os automóveis, o palpitar, o papo dos porteiros - se acelerar.

A lua cheia resplandece enquanto disparos de armamento pesado espocam no morro do Pavão: estilhaços sobre Copacabana, ruídos de uma useira beligerância. Fragmentos de outra guerra - ou, talvez, de diferentes batalhas do mesmo conflito: sob marquises, diversas pessoas amontoam-se, envoltas em parcos cobertores. Dormem. São famílias inteiras, grupos de amigos ou desconhecidos. Vivem na rua, expostos em tempo integral a tudo o que ela pode propiciar. Às cinco, noite quase dia, um respeitado profissional liberal encharcado de psicotrópicos vara a rua Duvivier procurando amigos que ainda não conhece. Travestis o intimam, machões o intimidam. Seduzido e vilipendiado, ele passa mudo e atuante na encruzilhada dos discursos. Às sete, no rabo da madrugada, findando o turno do BarBarela, uma puta enfastiada do frenesi tece tristes comentários escorada no ombro do compreensivo leão de chácara. Calção, camiseta e tez trigueira, um senhor caminha em direção ao calçadão à procura de sol e saúde. Ele não é o único. Aurora no bairro: uns vomitam, outros malham; poucos dormem, muitos acordam. Tudo em Copacabana.

Agora é manhã e há pouco espaço nas vias mais movimentadas. Nossa Senhora de Copacabana e Barata Ribeiro drenam povo a múltiplos destinos. Se correr o bicho pega, se ficar o bicho come. O dito ainda é o mesmo que intitulava a peça de teatro da década de 1960; a ditadura, porém, é outra. O ritmo é rápido. In- 
finitos indivíduos marcham rumo ao compromisso: andam prá não desistir. Quase não se olham, quase não se falam: "Com ou sem açúcar?", "Tô com pressa, sai da frente", "Tem troco pra cinquenta?". Nos arredores da Siqueira Campos, centro do bairro, é tamanha a quizumba - cores, sons, odores - são tantas as pessoas, tantos os vendedores ambulantes - fruta, pulseira, um é três dois é cinco - que a arte do desvio é requisito básico ao transeunte. Gente prá cá e prá lá, chocando-se, xingando-se e marcando um churrasco de calçada pro final de semana.

Nas esquinas há bancas de revistas. Andando, um punhado de gente lê as manchetes dos jornais empoleirados. Um novo centroavante no Flamengo, a crise política em Brasília, o assassinato de um bandido - retrato com venda nos olhos, legenda e as iniciais. Dependurados, centena ou mais de cartões postais: coqueiral e mar azul; Rio de Janeiro de vitrine, for export. O mais desavisado talvez dissesse, não sem certa razão, ser Copacabana deveras fotogênica. Outra fotogenia: dito isso e torcido o pescoço, três passos atrás o olho bate em uma família que pede clemência e clama por centavos. O clamor repete-se. Passa uma, passam duas, passam três pessoas e é como se clamor não houvesse. Duas marquises ao lado, três negrinhos perdem o prumo no cheiro forte da anestesia cotidiana. No prédio ao lado, uma senhora apressada e de olhar assustado, ressabiada pelo assalto que certa vez sofreu e pelas notícias diárias do jornal que lê, destranca a terceira fechadura do portão. Zelo corriqueiro: é a tranquilidade cercada que lhe permite a paz da evitação da diferença. No mesmo instante em que a senhora trava o portão, do outro lado da rua, dois camelôs conversam: falam do calor, da fiscalização, da morena que acaba de passar, do filho que está crescido. Cumprimentam os passantes conhecidos e fazem troça com o lojista parado às costas enquanto esperam a quentinha.

Já na primeira hora da tarde, velhos se reúnem na praça Serzedelo Correia. Jogam damas, xadrez, dominó e carteado. Tal qual aduana, as grades da praça - protegidas por dois policiais desde sua abertura até o seu fechamento - findam por delimitar os fluxos do espaço público, tornando-o como que uma extensão de espaço privado: a praça - armadilha de linguagem - é pleno lugar comum. No lado de dentro, mendigos e meninos de rua não são bem-vindos: eles não possuem o passaporte figurado em asseio. Grudados no metal enferrujado, dois garotos dividem o que resta de loló. Aceitos e bem-vindos, os ditos cidadãos de bem - estranho e frágil critério - deixam o tempo correr e jogam conversa fora. Babás e mães tricotam enquanto suas crianças bem nutridas divertem-se no playground. Ao final da tarde, fecham-se os portões da Serzedelo Correia. Aqueles que lá estiveram por algumas horas são obrigatoriamente devolvidos ao vão do espaço misto da rua. Fora da clausura, confrontam-se novamente com o desencontro e a diferença: “Tio, tem um trocado pra me dar?", "Será que não sobrou uma roupa na casa da senhora?". O retorno ao lar pode render muitos sobressaltos e fricções. No ponto, trabalhadores aguardam o ônibus que os levará de volta ao lar. Â espera, conversam; falam e escutam, mesmo que alheios aos que naquele instante ocupam o mesmo espaço: os telefones celulares estão grudados nas orelhas, e suas falas ecoam longe, muito longe. Numa esquina, um grupo de rapazes trajando o clássico uniforme da rede pública de ensino está à toa: atualização 
da fofoca, anedota passada adiante, um beijo ocasional. É a calçada servindo de palco de convivência, escapando pela tangente dos usos burocráticos - passagem, deslocamento, aceleração - que é quase forçada a ter. Próximos, uma senhora idosa e um rapaz de meia-idade andam pela avenida. Dobrando a esquina na rua Hilário de Gouveia, ela chega a tempo para a missa das seis. Alguns metros adiante, ele se permite comemorar o fim do turno na sex shop com shows de strip-tease ao vivo. Costas com costas, votos de castidade e orgasmos. Em Copacabana a noite vem antes do sol se pôr.

$\mathrm{Na}$ contramão do monstruoso engarrafamento, o pedestre em marcha satura-se de imagens de produtos expostos em vitrines. Roupas - for sale e em liquidação -, bugigangas pra turistas, eletrodomésticos. Colada à calçada, uma cidade em oferta, permanentemente sugando os olhos do passante. Enquanto o trânsito para, as mercadorias não cessam de fazer circular a falta e a consequente necessidade de consumo. O último lançamento, absolutamente fundamental para impedir a obsolescência do cidadão. O novo rondando e fazendo rota e esfarrapada a peça publicitária divulgada horas atrás. Não à toa, uma quantidade enorme de lixo é produzido e depositado dia a dia nas calçadas. Andando pela Nossa Senhora de Copacabana o contraste entre a novidade da semana e o lixo diário assusta: um jovem fotografando com o celular e um velho implorando $\mathrm{R} \$$ 0,25 para inteirar a quentinha.

Seguindo por tal via chega-se a mais uma praça. Na Sarah Kubitscheck - espaço dedicado à terceira idade - um muro separa o dentro e o fora. Muro que, em princípio, ofereceria menores possibilidades de porosidade do que quaisquer grades espalhadas no corpo urbano. De fato, o que ocorre por trás das paredes está vetado à visão da rua. A recíproca, obviamente, é verdadeira. Anuncia-se a impossibilidade de atravessamentos visíveis. No mural azulejado, todavia, há algo que chama a atenção: um painel representando estilizados jogadores de frescobol. Homenagem ao local - entre os postos cinco e seis - no qual se afirma ter nascido esse curioso jogo que prescinde de vencidos e vencedores. A praça - mesmo que murada, não permitindo a visibilidade extra-fronteiras - de certo modo faz jus à homenagem. Sem qualquer sinal de impedimento de ires e vires, a praça vira a paisagem na qual um casal de idosos diverte-se em sua pudica paquera, um avô ensina o neto a fazer aviões de papel e senhoras fofocam, enciumadas e elogiosas para com a beleza de um casal de jovens namorados.

A despeito de ser dedicada à terceira idade, os muros da praça Sarah $\mathrm{Ku}$ bitscheck não operam impedimentos à entrada de sujeitos de outras faixas etárias. A remissão ao frescobol do mural justifica-se: trata-se de um esporte no qual a partir do esforço mútuo objetiva-se não deixar a bola cair; esporte no qual se corporifica um jogo coletivo e singular ao mesmo tempo, sem que, para que haja vitória, tantos outros tenham de perder. Ou, por outra, a vitória ali é a continuação do embate. Mesmo dedicado à terceira idade, naquele espaço os tantos outros fluxos possíveis não foram impedidos. A afirmação de si, ali, independe do ataque ao outro. O painel que convida os idosos não segrega os não-idosos. A diferença, ali, não veste os trajes da desigualdade. Faz-se para além de um muro qualquer. 
Sito entre as ruas Barata Ribeiro e Raul Pompeia, o túnel Sá Freire Alvim cavouca o sopé do morro do Pavão. Carros e ônibus passam furiosos, berrando velozes e espargindo gás carbônico. Nas passarelas laterais da via, o cheiro forte de dejetos humanos faz adivinhar a presença de lixos os mais diversos. Espaço desvalido, apto a receber os restos de quem lá estanca, seleciona fluxos pedestres a partir do medo e do asco. A idéia de pura passagem desmonta-se logo de entrada: cobertores e restos de marmitas espalhados pelo chão fazem ver o paliativo de várias moradas. A passagem acelerada não pode ver o habitat do lixo não reciclável.

Duas centenas de metros adiante, na esquina das ruas Raul Pompeia e Francisco Sá, já quase em Ipanema, está o Parque Peter Pan, que, em verdade, é uma praça dedicada à convivência de crianças. E elas, de fato, tomam conta do espaço: correm prá cá e prá lá, gargalham, berram, brigam, choram. Na mesma tarde em que na outra praça um garoto aprendia a fazer aviões de papel com seu avô, uma moreninha babava-se inteira com o Chicabon, um gordinho deslizava faceiro sobre seu tênis com rodinhas, dois irmãos se estapeavam e desesperavam a jovem mãe. Cenas que fazem supor uma efervescência na praça. De fato, a suposição não é falsa: pequenos acontecimentos pululam naquele espaço.

Ali, todavia, as regras e vetos são vários: proibida a entrada de crianças desacompanhadas, de adultos sem camisa e sem crianças, de crianças com skates e com bolas. A estreita legislação incorre em uma infeliz tentativa de mecanização dos encontros possíveis. Ali, dentro da área gradeada, somente infantes e seus responsáveis fazem acontecer. A candura de certos olhares infantis tromba de frente com os limites do andante que não pôde entrar por não ter filhos. Do lado de fora, vê as grades impossibilitarem encontros entre diferentes faixas etárias.

O frescobol não vinga; o jogo ali é outro. Em seu interior, a praça representa o simulacro do traçado de um trânsito urbano, paraíso simultâneo das normas e da individualidade. Autorização de alguns fluxos, freio de outros. Sinal aberto aqui, sinal fechado acolá. Tudo intencionalmente controlado para que nada entre em choque e se desassossegue. Nem um caminhão no contrafluxo, nem um adulto surpreso com a surpresa do olhar infantil. Os encontros dissonantes ficam todos na virtualidade da imaginação, aquém de quaisquer grades.

Agora é noite e ferve o calçadão. Meninas com peitinhos de pitomba vendem suas bugigangas. Um sueco de cor rosa pede ajuda e pechincha uma morena jambo. Dois alemães, metro e noventa de altura e reais transbordando da carteira, já compraram a oferta da semana. Em frente ao hotel de luxo, mãos dadas aos sorridentes souvenires, sorvem caipirinhas e desfilam. Pivetes passam em desabalada carreira, instantes após confundirem turistas ingleses com americanos e lhes tomarem a máquina fotográfica digital: vão comê-la, cheirá-la, fumá-la. Com ela vão fotografar. Espalhando os produtos a céu aberto, artesãos e camelôs apropriam-se de uma pequena fatia do espaço na tentativa de recolher alguns tostões. Truculentos policiais, aos gritos e safanões, retiram dali as mercadorias e os mercadores. "Tira essa merda daqui e vai embora!". Ao redor, quiosques e restaurantes - com as mesas postas na mesma calçada da qual há alguns instantes foram extirpados os pequenos comerciantes sem alvará - fartam-se de capital estrangeiro. Metros 
acima se vêem as muitas luzes azuladas das telas de televisão piscando nas janelas dos apartamentos. É hora da novela. Olho fixo no écran, um senhor troteia na esteira, sequer cogitando exercitar-se na pista de areia fofa que dista alguns metros de seu prédio. Fora do apartamento, por detrás da janela gradeada, a cidade observa sua solidão. Andares acima uma senhora - outra solidão - manda e-mail para a filha que vive na avenida das Américas: com a vizinha com a qual costumava tomar a fresca já quase não fala; ela está distante - ainda não se acostumou às lides da internet: como diz o ditado, quem sabe, cyber, quem não sabe, sobra. Esfomeado, um adolescente encomenda uma pizza por telefone: o restaurante do outro lado da rua, do outro lado da grade, parece longe demais. Cercar-se é preciso, viver não é preciso. Pescadores debocham da máxima e atiram tarrafas e anzóis ao mar. Conversam, bebericam um trago ou outro de cerveja, deixam o tempo passar. Enquanto pescam, iluminados por potentes refletores, um mendigo doido, gordo e de barbas e cabelos longos e desgrenhados rola no mar raso. Afoga-se e brinca, engole água, ri e grita. Quase ninguém - esportistas, pescadores, guardas e garis - o percebe. Quase ninguém - esportistas, pescadores, guardas e garis - demonstra percebê-lo. Mas ele está lá, habitando a sombra e compondo a cena no mar agressivo de Copacabana. Ele desacomoda o tradicional cartão postal.

Agora é domingo. Já cedo, a pista da Avenida Atlântica é furtada dos automóveis e ofertada aos transeuntes. Bate sol e a areia é pouca. De dentro dos lares vaza a classe média em trajes de banho. Pavão e Tabajaras estão lá também. Contraste aos pretos, a brancura gringa faz arderem os olhos. É um mundo na orla de Copacabana. Biscoito Globo, mate, altinha, New York Times. "Hay the color bleu, madame". Nas incontáveis quadras esportivas da beira da praia, amigos e desconhecidos travam batalhas. Corpos confluem: a violência de uma jogada dura ou o abraço que celebra o tento marcado. Sob lonas e barracas, famílias - consanguíneas ou não - desfrutam dos prazeres do encontro. Cervejas, caipirinhas e baseados amolecem os corpos. Ocupam-se áreas sem usura. Hora que outra, o helicóptero da polícia faz a ronda e não deixa que se olvide: são tempos de guerra. Meio de tarde, grupos se reúnem em todo botequim. Pedem mais uma rodada, brindam a sabe-se lá o quê. Abraçam-se, riem, discutem. As mesas e as cadeiras estão na calçada, dedicando a Dioniso o espaço que, se não fosse de todos, seria de ninguém. Por ali as grades somente serão vistas à hora de fechar, quando os confrades - rotineiros ou ocasionais - antevendo a ordinária ressaca, pedem a saideira e conferem se a chave do portão segue no bolso. Do comum espaço da rua, irão - talvez em ziguezague - enfurnar-se detrás das barras de ferro que lhes garantem a segurança. Enquanto na Avenida Atlântica os automóveis tomam de volta o espaço que é necessário que lhes pertença, os boêmios voltam a onde o passeio começou. $\mathrm{E}$, nesse mesmo instante, há muitos acontecimentos $\mathrm{e}$ existências transbordando os muros e grades em Copacabana. Oxalá. 


\section{Nota}

${ }^{1}$ Tal conceituação está trabalhada com mais calma e detalhamento em um capítulo exclusivamente dedicado ao tema na supracitada dissertação a qual inspira o presente artigo.

\section{REFERÊNCIAS}

ANTÔNIO, J. Ô, Copacabana! São Paulo: Cosac \& Naify, 2001.

BAPTISTA, L. A. A cidade dos sábios. São Paulo: Summus, 1999.

BENJAMIN, W. Charles Baudelaire: um lírico no auge do capitalismo. São Paulo: Brasiliense, 1989.

. (Org.). Imagens de pensamento. São Paulo: Brasiliense, 1987. v. 2. Coleção Obras escolhidas de Walter Benjamin.

BRAGUINHA; RIBEIRO, A. Copacabana. Intérprete: Dick Farney. Orquestração de Radamés Gnattali. Rio de Janeiro: Continental, 1946.

CABRAL, A. Subjetividades e espaços: narrativas incompletas. 2006. Dissertação (Mestrado)—Universidade Federal Fluminense, Niterói, 2006.

CARDOSO, E. D. et al. Copacabana: história dos bairros. Rio de Janeiro: Index, 1986.

DELEUZE, G.; PARNET, C. Diálogos. Lisboa: Relógio D’Água, 2004.

FAWCETT, F. Rio 40 graus: purgatório da beleza e do caos. In: PEREIRA, R.; VIEIRALVES, R. (Org.). Rio 40 graus: beleza e caos. Rio de Janeiro: Quartet, 2002. p. 34-37.

FERREIRA, M.S.Acidade comoum texto: fragmentos da experiência homossexual masculina no Rio de Janeiro contemporâneo. 2006. Tese (Doutorado)—Pontifícia Universidade Católica do Rio de Janeiro, Rio de Janeiro, 2006.

GAGNEBIN, J. Posfácio: uma topografia espiritual. In: ARAGON, L. O camponês de Paris. Rio de Janeiro: Imago, 1996. p. 241-259.

LAVINAS, L.; RIBEIRO, L. C. Q. Imagens e representações sobre a mulher na construção da modernidade de Copacabana. In: SOUZA, C. F.; PESAVENTO, S. J. Imagens urbanas: os diversos olhares na formação do imaginário urbano. Porto Alegre: UFRGS, 1997. p. 45-53.

LESSA, C. O Rio de todos os brasis. Rio de Janeiro: Record, 2000.

VELHO, G. A utopia urbana: um estudo de antropologia social. Rio de Janeiro: J. Zahar, 1989.

Recebido em: maio de 2009

Aceito em: julho de 2009 